\title{
Pembaruan Kontrol Sistem Indonesia LoW SPEEd TUNNEL
}

\section{UPGRADE CONTROL SYSTEM INDONESIA LOW SPEED TUNNEL}

\author{
Franky Surya Parulian' \\ ${ }^{1}$ Balai Besar Teknologi Aerodinamika, Aeroelastika dan Aeroakustika (BBTA3) \\ (National Laboratory for Aerodynamics, Aeroelastics and Aeroacoustics Technology) \\ Kawasan PUSPIPTEK Ged 240, Setu, Tangerang Selatan-15314, INDONESIA
}

\begin{abstract}
Abstrak
Indonesian Low Speed Tunnel (ILST) telah beroperasi sejak Pebruari 1987, dimana dalam operasinya didukung oleh 10 unit plant fasilitas-ILST, dimana plant fasilitas-ILST bekerja sesuai tugas plant masing-masing dan dapat dioperasikan secara local control (onsite) dan secara remote dari ruang kontrol (desk control). Pengoperasian secara local dan remote tersebut dimungkinkan dengan pemasangan kontrol sistem pada masing-masing plant fasilitasILST, kontrol sistem yang digunakan adalah Programmable Logic Controller (PLC), yang dipasang di tiap plant fasilitas-ILST sebagai local PLC dan central PLC.

Untuk operasi remote dimana dipasang module komunikasi pada local dan central PLC. PLC yang digunakan ILST adalah SATTControl yang menggunakan operating system CPM yang tak umum lagi digunakan saat ini dan sulit mencari spare part karena produsen PLC telah mengkonfirmasi bahwa tak ada lagi dukungan teknis dan spare parts sejak tahun 2001.

Untuk kelangsungan operasi ILST dilakukan pembaruan kontrol sistem ILST, pembaruan meliputi pemeriksaan PLC lama, survey PLC baru di dalam negeri, kecocokan dengan PLC existing, flexibilitas hardware dan software yang berbasis windows, komunikasi antar PLC, kehandalannya dan sesuai dengan dana yang diperoleh tiap tahun.
\end{abstract}

Katakunci: control system ILST, PLC

\begin{abstract}
Indonesian Low-Speed Tunnel (ILST) has been in operation since February 1987, whose operation is supported by 10 units of the ILST-facility plant, each ILST-facility plant works according to its duties and can be operated locally (onsite) and remotely (from control room/control desk). Local and remote Operations are made possible by system control's installation at each ILST-facility plant. The control systems used are the Programmable Logic Controller (PLC), which is installed at each -ILST facility plant as local PLC and central PLC.

For remote operations, a communication module is installed at local and central PLC. The PLC used by ILST was SATTControl running CPM operating system which is not commonly used anymore, and the spare parts are difficult to find because the PLC manufacturers have confirmed that they no longer provide technical support or spare parts since 2001.

To ensure ILST's continues operations, ILST's control system update is carried out. The updates include old PLC checks, new locally available PLC surveys, compatibility with existing PLCs, windows-based hardware and software flexibility, inter PLCs communication, system's reliability and suited with yearly available budget.
\end{abstract}

Keywords: ILST system control, PLC

\section{Pendahuluan}

Indonesian Low Speed Tunnel (ILST) atau terowongan angin kecepatan rendah Indonesia merupakan salah satu fasilitas pengujian ilmu aerodinamika yang dimiliki Balai Besar Teknologi Aerodinamika

* Franky Surya Parulian.Tel: +62 217560902

E-mail: franky.surya@bppt.go.id Aeroelastika dan Aeroakustika dibawah naungan Badan Pengkajian dan Penerapan Teknologi 
(BBTA3 - BPPT). ILST digunakan untuk mendukung riset dan pengembangan ilmu aerodinamika dan industri aerodinamika di Indonesia.

Terowongan angin bertipe atmospheric closed circuit dan beroperasi sampai kecepatan udara 110 m/detik, yang dibangun sejak tanggal 18 Desember 1984 dan beroperasi sejak 7 Pebruari 1987, bekerjasama dengan NLR-the Netherlands.
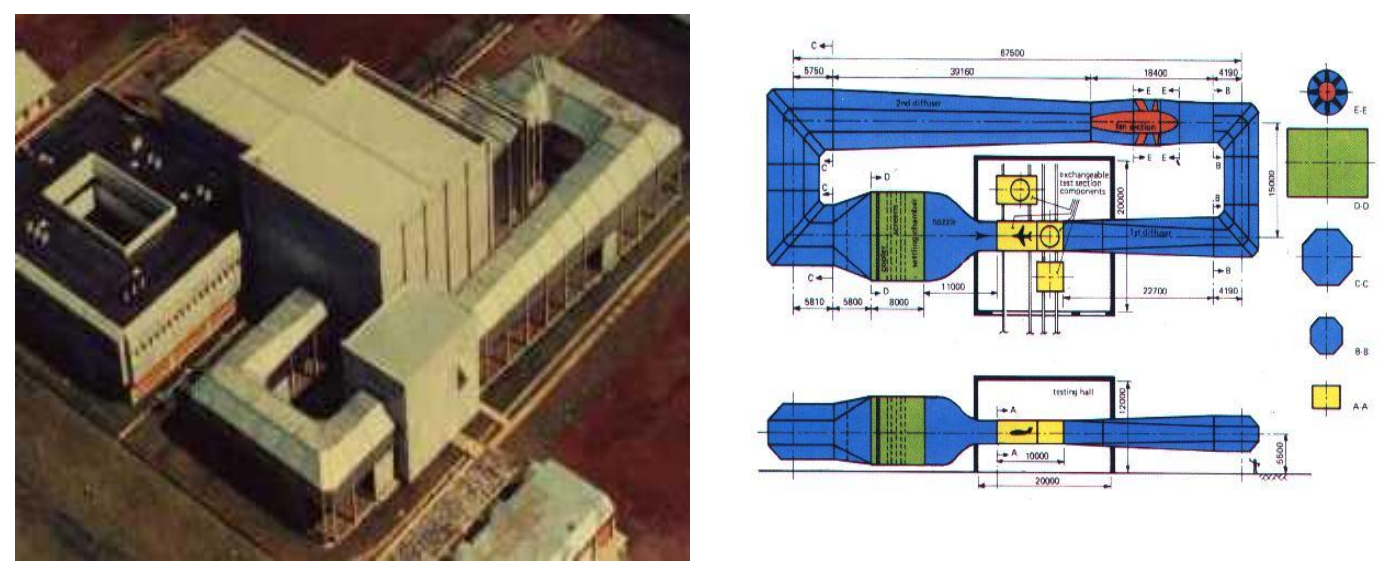

Gambar 1. Indonesian Low Speed Tunnel (ILST)

Dalam beroperasinya terowongan angin-ILST didukung oleh plant fasilitas-ILST, plant fasilitas- ILST terdiri dari sebagai berikut :

1. Seksi uji external balance

Seksi uji external balance sebagai tempat pengujian model uji pesawat terbang dengan menggantung melalui strut dari atas seperti gambar 2. Untuk pengukuran gaya dan moment aerodinamika mengunakan external balance, untuk fungsi seksi uji ini dilengkapi dengan mekanisme alpha untuk mengatur sudut serang $(\alpha)$ dan mekanisme beta untuk mengatur sudut yawing $(\beta)$. Sudut serang antara $-35^{\circ}$ sampai dengan $35^{\circ}$ dan sudut yawing $(\beta)-45^{\circ}$ sampai $45^{\circ}$.

2. Seksi uji sting support

Seksi uji sting support sebagai tempat pengujian model uji pesawat terbang dengan menggantung melalui lengan sting dari belakang seperti gambar 3. untuk pengukuran gaya dan moment aerodinamika mengunakan internal balance, untuk fungsi seksi uji ini dilengkapi dengan mekanisme alpha untuk sudut serang $(\alpha)$ dan mekanisme beta untuk sudut yawing $(\beta)$.

Sudut serang antara $-65^{\circ}$ sampai dengan $65^{\circ}$ dengan sting sudut $0^{\circ}$ dan sudut serang antara $-85^{\circ}$ sampai dengan $85^{\circ}$ dengan sting sudut $55^{\circ}$ dan sudut yawing ( $\beta$ ) -30 sampai $30^{\circ}$.

3. Seksi uji industrial

Seksi uji industrial sebagai tempat pengujian model uji bukan pesawat terbang seperti gedung tinggi, jembatan span panjang, kapal laut dll., untuk pengukuran gaya dan moment aerodinamika dengan sudut yawing $(\beta)$ sampai $180^{\circ}$, untuk fungsi seksi uji ini dilengkapi dengan mekanisme beta.

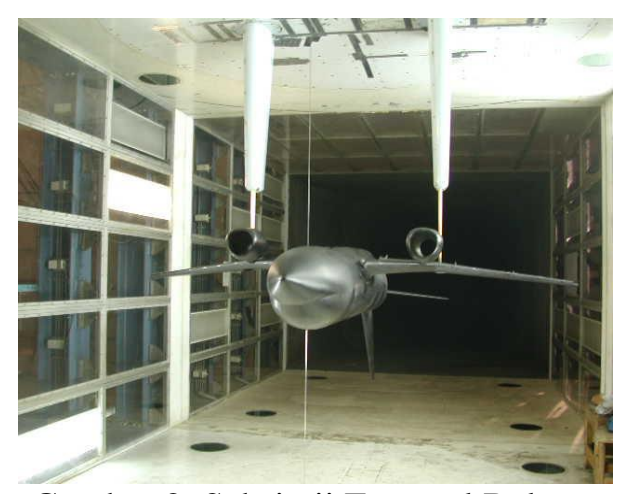

Gambar 2. Seksi uji External Balance

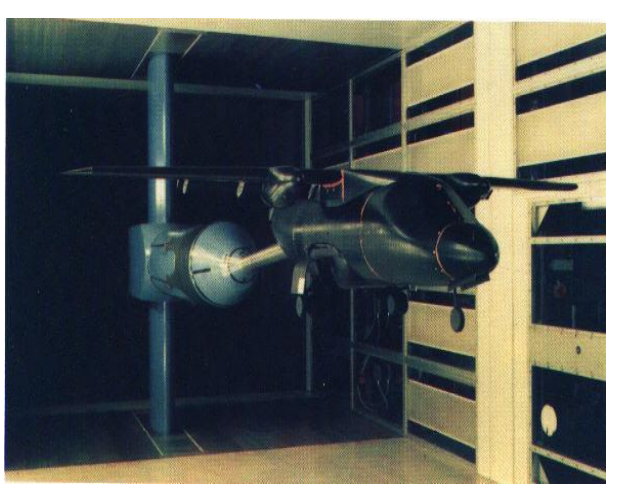

Gambar 3. Seksi uji Sting Support 
4. Seksi uji empty box

Seksi uji empty box sebagai tempat pengujian model uji bukan pesawat terbang untuk pengukuran gaya dan moment aerodinamika dengan sudut yawing $(\beta)$ sampai $180^{\circ}$, untuk fungsi seksi uji ini dilengkapi dengan mekanisme beta.

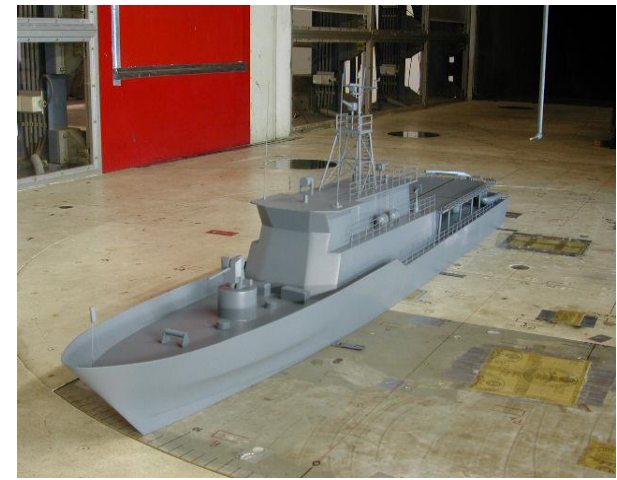

Gambar 4. Seksi uji Empty Box

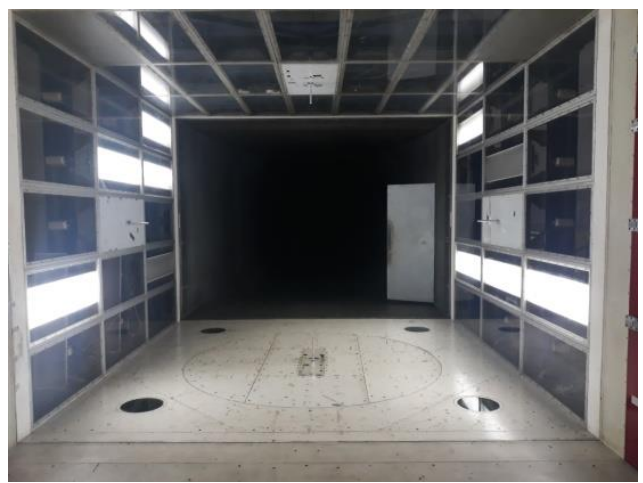

Gambar 5. Seksi uji Industrial

5. Fan drive

Fan drive merupakan plant fasilitas-ILST yang digunakan untuk menghasilkan aliran udara di dalam terowongan angin sampai kecepatan $110 \mathrm{~m} /$ detik dengan memutar motor DC 2.1 Mega Watt melalui DC drive.

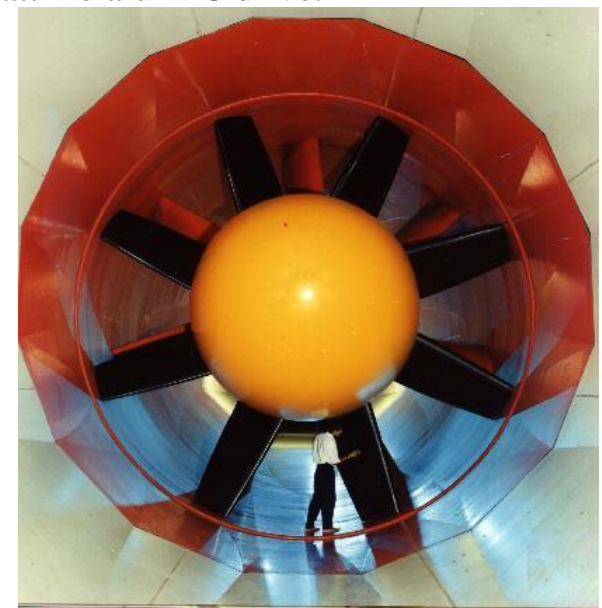

Gambar 6. Motor 2.1 MW dan fan blade

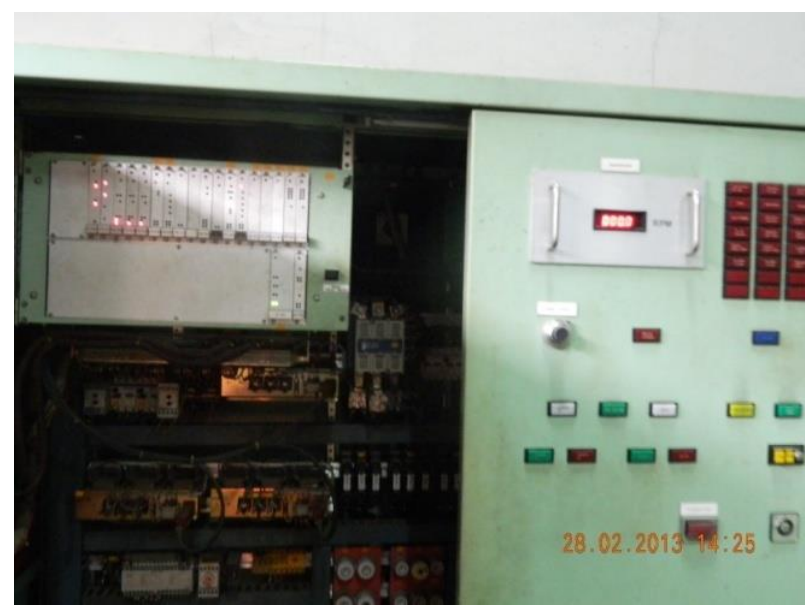

Gambar 7. DC Drive

6. Cooling system

Cooling system, plant fasilitas-ILST untuk mengendalikan suhu aliran udara di dalam terowongan angin dengan mengalirkan air dari bak air ke sirkuit terowongan angin dan kembali ke bak air dengan teknologi heat transfer.

7. Compress air system (CAS)

Compress air system, plant fasilitas-ILST digunakan untuk menghasilkan udara bertekanan tinggi sampai 60 bar yang disimpan di tabung tekanan tinggi (Vessel)

Udara bertekanan tinggi di gunakan untuk pengujian model uji pesawat terbang dengan engine (Power On). 


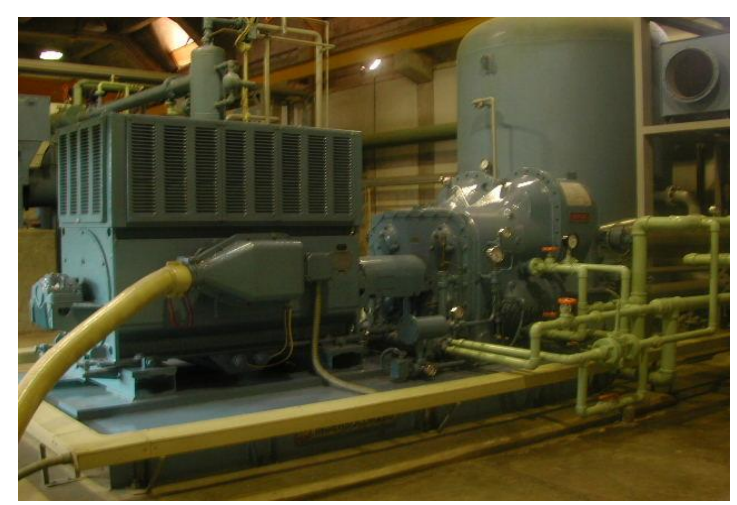

Gambar 8. Compressor

8. Air distribution system (ADS)

Air distribution system, plant fasilitas ILST yang bertugas untuk mengatur dan mengalirkan udara bertekanan tinggi dari tabung tekanan tinggi ke Massflow Control system untuk pengujian model uji pesawat terbang dengan engine (Power On).

9. Massflow control system (MCS)

Massflow control system, plant fasilitas-ILST yang bertugas mengalirkan udara bertekanan tinggi dan mengaturnya aliran sesuai dengan massa yang dibutuhkan pada pengujian model uji pesawat terbang dengan engine (Power On).

\section{Mekanisme traversing}

Mekanisme traversing, plant fasilitas-ILST yang digunakan untuk tempat memasang instrument ukur yang dapat di pindahkan di jalur travelnya dari sisi kiri ke kanan atau sebaliknya di seksi uji.

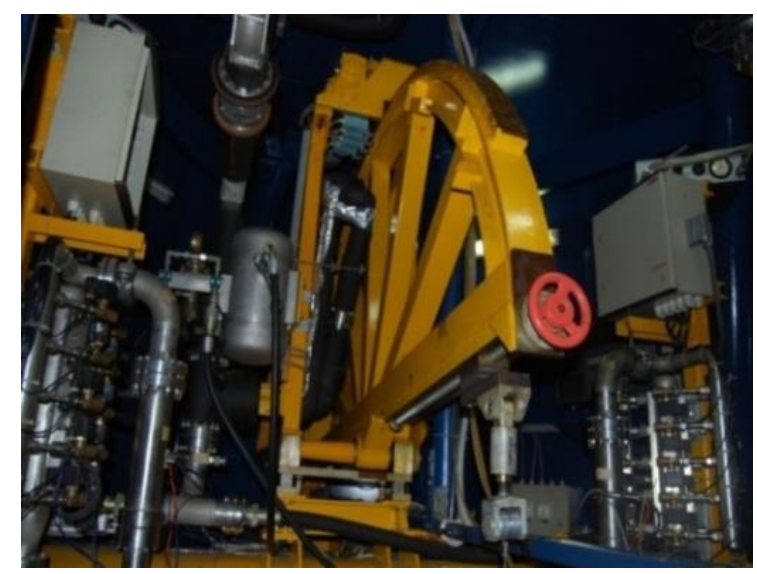

Gambar 9. Massflow Control System

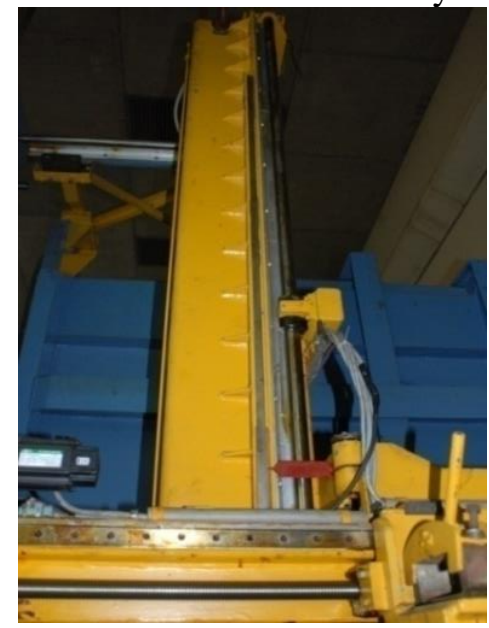

Gambar 10. Mekanisme Traversing 


\section{KONTROL SISTEM ILST}

Kontrol sistem terowongan angin-ILST mengatur kerja plant-plant fasilitas ILST untuk dioperasikan pada pengujian model uji aerodinamika, dimana konfigurasi pengunaan seksi uji plant fasilitas-ILST untuk pengujian model uji aerodinamika di terowongan angin-ILST sebagai berikut :

1. Seksi uji External balance - Industrial.

2. Seksi uji External balance - Sting support.

3. Seksi uji Empty box - Industrial.

4. Seksi uji Empty box - Sting support.

Dalam operasi pengujian terowongan angin-ILST difungsikan plant fasilitas-ILST lain sebagai plant dominan dan pendukung sesuai kebutuhan pengujian sebagai berikut :

1. Fan drive.

2. Cooling system.

3. Compress Air Sistem (CAS).

4. Air Distribution Sistem (ADS).

5. Massflow Control Sistem (MCS).

6. Mekanisme Traversing.

Dalam pengoperasian terowongan angin-ILST plant fasilitas dapat dioperasikan dari tempat plant terpasang secara local kontol dan dapat dioperasikan secara remote dari ruang kontrol-ILST, untuk itu maka disetiap plant fasilitas-ILST dipasang kontrol sistem untuk lokal kontrol dan Central kontrol sistem untuk operasi remote dari ruang kontrol.

Kontrol sistem yang digunakan adalah programmable logic controller (PLC).

Komunikasi antara central PLC dan local PLC menggunakan interface komunikasi RS-485.

Central PLC bertugas untuk mengatur kerja semua plant fasilitas-ILST melalui local PLC untuk kontrol monitor yang terintegrasi ditambah safety system pengoperasian terowongan angin-ILST seperti gambar 11 .

Kontrol sistem yang digunakan programmable logic controller (PLC) Sattcontrol SC-15, SC-31 untuk local PLC dan SC-60 untuk central PLC.

SattControl PLC menggunakan microprocessor MC-6800 untuk SC-31 dan MC-68000 untuk SC-60 dengan operating system CPM (Control Process Monitor) generasi sebelum DOS (Disk Operating System) yang digunakan oleh computer Apple II.

Sejak tahun 1996 PLC SattControl telah mengalami banyak masalah teknis, umumnya pada module processor dan komunikasi antar PLC.

Untuk mendapatkan spare parts diperoleh dari institusi lain pendukung BBTA3 yakni NLR Belanda dengan waktu 8 minggu dan harga yang relative mahal, karena sulit diperoleh di dalam negeri.

Pada akhir tahun 1998 dan 2001 produsen SattControl telah memberikan konfirmasi bahwa tidak lagi memsupport secara teknik untuk SC-31 dan tahun 2001 untuk SC-60 disamping itu untuk mencari operating system CPM sulit didapat. Untuk kesinambungan operasi terowongan anginILST perlu dilakukan pembaruan kontrol sistem ILST.

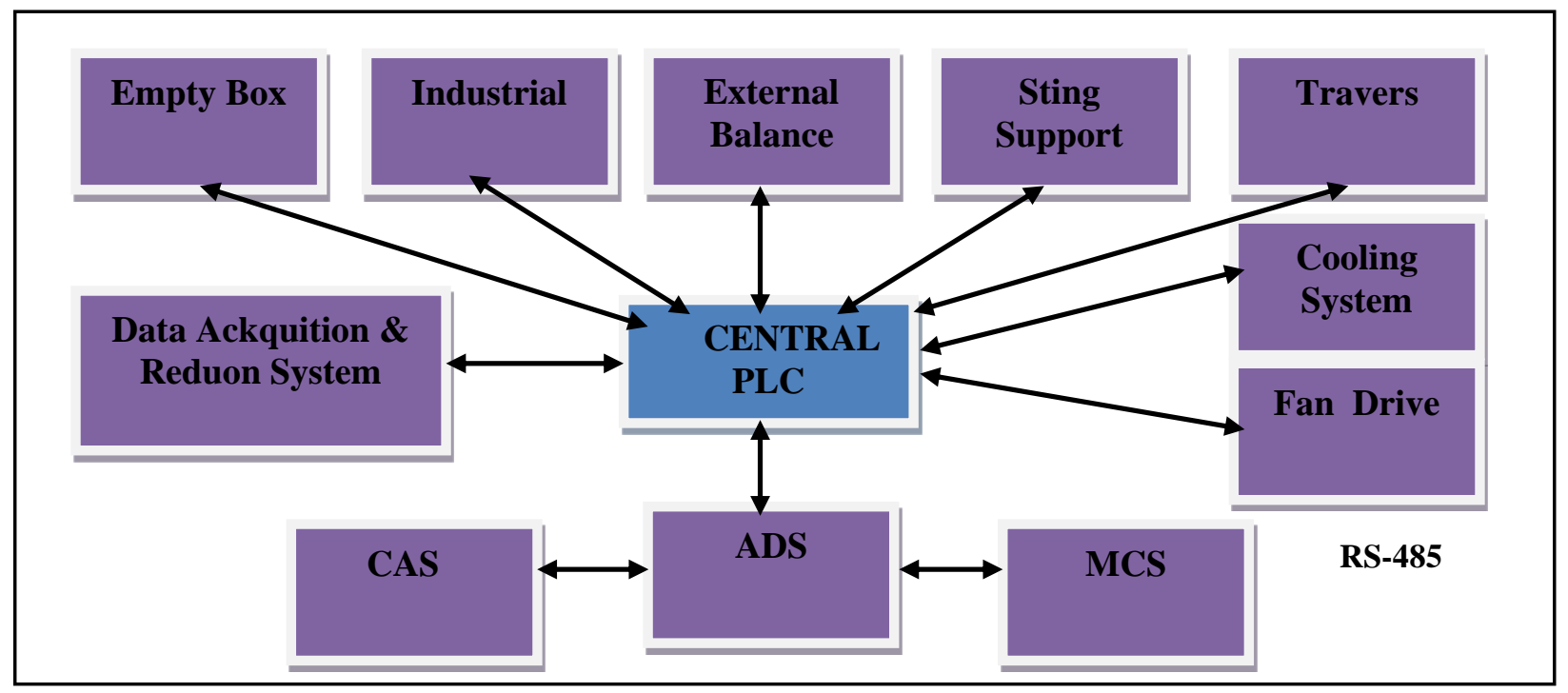

Gambar 11. Konfigurasi Kontrol Sistem ILST 


\subsection{Rumusan Masalah}

Setelah lebih dari dua belas tahun beroperasi terowongan angin-ILST, mengalami banyak masalah baik operasi plant fasilitas-ILST maupun perawatannya sebagai berikut :

1. Menggunakan operating sistem CPM, operating sistem sebelum DOS (Disk Operating Sistem) yang saat ini sulit diperoleh dipasaran baik dalam negeri maupun luar negeri.

2. Komunikasi antara central PLC dan Lokal PLC sering terputus dimana komponen module komunikasi sering rusak.

3. Dengan usia operasi seperti diatas yang tidak diiringi dengan perawatan sistem grounding, disaat frekwensi hujan tinggi, PLC mudah terserang petir.

4. Dari produsen PLC SattControl telah memberi konfirmasi bahwa support spare part dan dukungan teknis telah habis pada tahun 2001.

5. Sulit mendapatkan spare parts di dalam negeri dan PLC masih diperlukan pada plant fasilitasILST.

6. Untuk kesinambungan operasi terowongan angin-ILST maka perlu dilakukan pembaruan kontrol sistem-ILST secepatnya.

\subsection{Tujuan dan Manfaat Penelitian}

Tujuan dari kegiatan adalah untuk mendapatkan kontrol sistem baru yang cocok, dengan fleksibilitas tinggi, kecepatan lebih tinggi, sesuai dengan ketersediaan dana yang didapat dari kegiatan dan dapat digunakan pada plant-fasilitas-ILST dan dapat berkomunikasi dengan PLC SattControl existing.

Manfaat kegiatan adalah tersedianya kontrol sistem baru yang siap digunakan pada plant-fasilitasILST dan dapat dioperasikan untuk menunjang operasi terowongan angin-ILST.

\section{METODE}

\section{A. Rancangan Penelitian Pembaruan Kontrol Sistem ILST}

Setelah lebih dari 12 tahun beroperasinya kontrol sistem ILST, untuk mendukung pengujian model uji aerodinamika di terowongan angin-ILST, mengalami penurunan unjuk kerjanya, dimana sering terjadi kerusakan teknis.

Penangulangan masalah teknis kontrol sistem telah dilaksanakan dengan mengganti komponen (hardware) dari dalam negeri dan pemesanan spare parts ke Belanda memerlukan waktu yang cukup lama dengan harga yang relative mahal, karena pengguna kontrol sistem yang digunakan ILST di Indonesia sedikit.

Perangkat lunak yang digunakan oleh SattControl adalah operating system CPM, dimana operating system ini digunakan sebelum operating system DOS, yang sulit ditemukan.

Untuk kelangsungan operasi ILST, dilaksanakan pembaruan kontrol sistem ILST, dengan ketersediaan dana untuk pembaruan kontrol sistem ILST dilaksanakan dalam beberapa tahapan, dimana pembaruan dilaksanakan setiap tahun.

Tahapan pembaruan kontrol sistem dilaksanakan sebagai berikut :

\section{Tahap-1 Observasi PLC}

Tahapan observasi dilaksanakan untuk mendapatkan kontrol sistem baru yang siap digunakan sebagai pengganti SattControl PLC, sebagai berikut :

\section{A. Observasi PLC existing dan PLC dipasaran dalam negeri}

Observasi PLC existing dan PLC baru dilaksanakan pada tahun 2001

1. PLC lama

Memeriksa PLC existing dan konfirmasi dengan produsen PLC,

Jumlah I/O PLC tiap plant,analog I/O, Digital I/O, processor, Software PLC, Programming, HMI dan lainya.

\section{Hasil observasi existing PLC}


PLC existing buatan swedia, menggunakan Operating system CPM

Programming menggunakan Ladder-mnemonic program.

Menggunakan Interface komunikasi RS-485, kapasitas memory RAM, ROM

- Lokal PLC Sattcontrol SC-31

- CPU dengan MC-6800.

- Input output $30-400$ point.

- Central PLC SattControl SC-60

- CPU dengan MC-68000.

- Input/output 1000 point.

2. PLC baru

Pelaksanaan observasi dengan penawaran dari produsen PLC existing dan mendatangi perusahaan pensupply PLC dalam negeri, melihat sarana pendukung teknis, spare parts, jumlah I/O, fleksibilitas PLC, komunikasi antar PLC, delivery time, garansi, harga produk, pelatihan dan lainnya.

Tahapan pelaksanaan dan hasil observasi PLC existing dan PLC yang ada dipasaran dalam negeri sebagai berikut :

a. SattControl

- SC-200 dan SC-300

- Hardware Bagus, langsung ganti, dengan kabel instalasi existing.

- Software PLC dengan windows OS, Ladder, SFC.

- HMI bagus.

- Harga relative mahal.

- Pihak SattControl menjamin penggantian PLC dapat dikerjakan dalam waktu 1 tahun kegiatan mencakup keseluruhan Kontrol sistem ILST.

- Dana yang tersedia terbatas.

- Ketergantungan dari luar negeri tak terputus.

b. Siemens

- Simatic S7-200, Simatic S-5

- Hardware Bagus.

- Software PLC dengan windows OS, Ladder, SFC.

- HMI Wonderware, bagus.

- Harga relative mahal.

- Pihak Siemens ingin seluruh plant dikerjakan langsung dalam 1-2 tahun kegiatan.

- Dana yang tersedia terbatas dan pelaksanaan tiap tahun.

c. Schneider

- Modicon Quantum

- Hardware Bagus.

- Software PLC dengan windows OS, single/full licence, Ladder, SFC.

- HMI dengan Intelution, Citech bagus.

- Harga relative mahal.

d. Mitshubishi

- MelSec Series

- Hardware Bagus.

- Software PLC dengan DOS OS, Ladder, SFC.

- HMI bagus.

- Harga relative mahal, lebih murah dibandingkan dengan PLC Siemens dan Schneider.

- Pelatihan PLC Mitsubishi. 


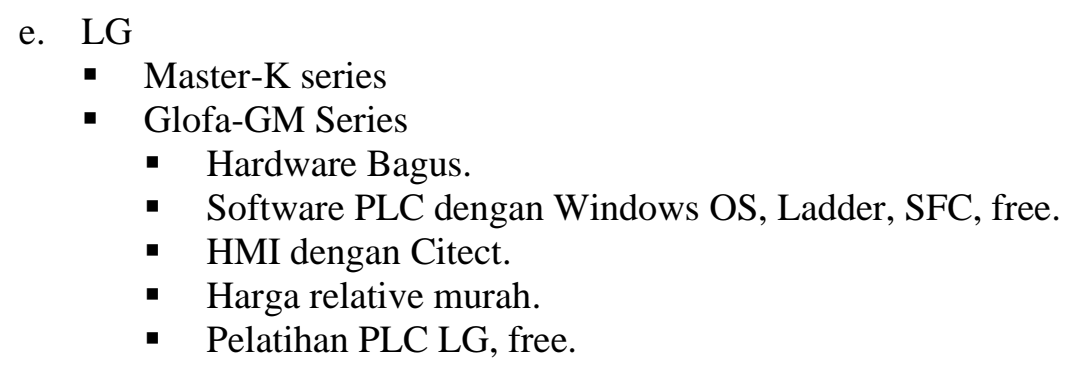

\section{B. Pengambilan Keputusan Pemilihan PLC}

Setelah pelaksanaan observasi, diputuskan hasil pemilihan PLC sebagai berikut :

1. Memutuskan PLC Mitsubishi MelSec Series akan digunakan sebagai pengganti PLC existing
a. Melaksanakan pelatihan PLC Mitsubishi MelSec Series.
b. Dalam pelaksanaan pelatihan diketahui PLC Mitsubishi MelSec menggunakan operating system DOS.
c. Dengan melaksanakan komparasi antara PLC Mitsubishi MelSec dan PLC LG, baik harga, hardware, software yang ditawarkan dari perusahaan pensupply, maka dilaksanakan.

2. Memutuskan PLC LG Glofa GM-4 series, digunakan sebagai pengganti PLC existing, dengan pertimbangan berikut :
a. Memiliki fleksibilitas tinggi.
b. Fasilitas user defined yang memungkinkan komunikasi dengan protocol berbeda.
c. Hardware bagus dengan jumlah I/O yang memadai, processor lebih cepat dari PLC lama.
d. Software bagus dan free.
e. Harga terjangkau dan sesuai dengan yang diperoleh dari kegiatan.

\section{Tahap-2 Pilot project}

Tahapan pilot project dilaksanakan untuk membuat prototype kontrol sistem baru yang dapat berkomunikasi dengan PLC SattControl dan dapat menggantikan PLC SattControl secara bertahap tiap tahun.

Untuk dapat digunakannya PLC LG di plant-fasilitas-ILST dilaksanakan sebagai berikut :

\section{A. Pilot project}

1. Pembuatan paket PLC untuk membuat komunikasi antara PLC baru (LG) dengan PLC lama SattControl SC-60.

2. Pembuatan paket PLC untuk membuat komunikasi antara PLC baru (LG) dengan PLC lama SattControl SC-31.

3. Dengan fasilitas User define PLC LG dapat membaca protocol PLC.

\section{B. Protocol Komunikasi Sattcontrol SC-60 dan SC-31}

Protocol komunikasi Sattcontrol SC-60 dan SC-31 menggunakan Protocol COMLI

\section{COMLI - Driver pada COMLI Protocol}

\subsection{Penggunaan Driver}

Driver di desain untuk pertukaran data antara SattConxx COMLI (COMuncation LINK) protocol ke PLC sistem lain.

Pertukaran data digunakan pada serial interface seperti RS-232 atau RS-485 standard. 
Pada driver versi ini fungsi protocol COMLI dipakai :Transfer individual I/O bits, Transfer I/O bits atau register, Request individual I/O bits, Request several I/O bits atau registers, Transfer tanggal dan waktu, Acknowledge.

\subsection{Deklarasi Channel Transmisi}

Deklarasi syntax penuh chanel transmisi bekerja sesuai dengan protocol COMLI yang diberikan sebagai berikut :

channel_name=COMLI, slave_no, port [, baud] [,parity] [,data_type]

Dimana : COMLI -nama driver;

slave_no-nomor slave yang di assigned untuk PLC yang digunakan;

port-nama serial port yang digunakan untuk koneksi dengan PLC yang akan dieksekusi;

baud- option: kecepatan transmisi; default 9600;

parity- option: parity check; default ODD;

Type data - option: data ASCII atau biner; default biner.

Contoh

Deklarasi transmissi channel yang dinamakan CHANNEL, yang digunakan untuk berkomunikasi dengan PLC dengan no. 3 melalui port COM2 pada default mode.

$9600 \mathrm{Bd}, 8$ bit character, check parity ODD, binary data: CHANNEL = COMLI, 3, COM2

\subsection{Communications Parameters}

High speed link parameters digunakan untuk men-set station lawan untuk komunikasi data, data dan silkus komunikasi untuk berkomunikasi data tertentu secara berulang melalui module komunikasi.

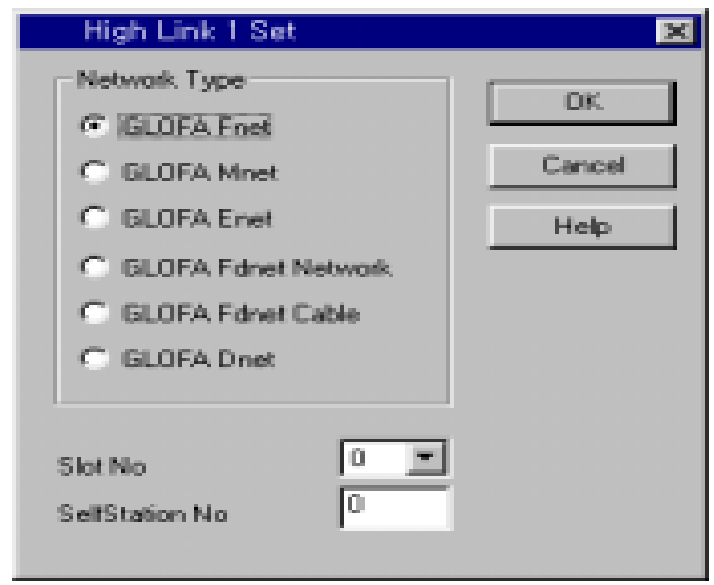

Gambar 12. Communications Parameters

Tipe Network : Digunakan untuk men-set tipe module komunikasi

Slot No. : Nomor Lokasi Slot dimana komunikasi module yang terpasang.

Local No. : nomorLocal module yang digunakan untuk mengeksekusi high speed link communications. 


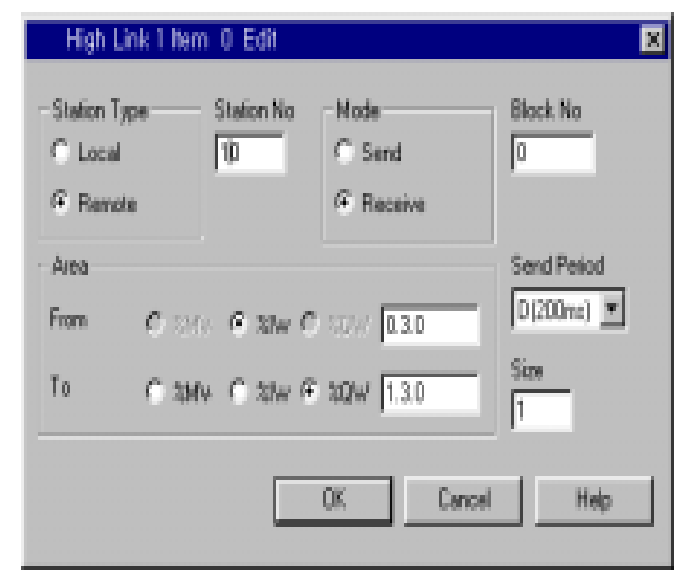

Gambar 14. Communications Parameters

(1) Jenis stasiun: Jenis modul komunikasi di stasiun yang berlawanan. Lokal atau remote akan diatur.

(2) Nomor Stasiun: Digunakan untuk menunjukkan stasiun yang telah memanggil data selama komunikasi.

(3) Mode: Digunakan untuk mengatur mode komunikasi ke Kirim atau Terima.

(4) Blok No: Merancang nomor untuk identifikasi blok data dalam modul komunikasi yang sama.

(5) Siklus komunikasi data: Digunakan untuk mengatur siklus pengiriman dan penerimaan data.

(6) Area: Area I, Q, dan M harus ditetapkan dengan angka desimal atau Word.

(7) Ukuran: Jumlah word yang akan dikirim dan diterima.

\subsection{Layanan User Defined Protocol}

Layanan user defined protokol digunakan ketika perangkat eksternal memiliki bentuk protokol yang berbeda dari modul Cnet dan pengguna bermaksud untuk berkomunikasi dengan perangkat eksternal dengan menggunakan protokol mereka sendiri.

1. Selama layanan, modul Cnet berfungsi sebagai master untuk perangkat eksternal, sehingga program PLC yang mengirim / menerima bingkai komunikasi diperlukan.

2. Frame komunikasi dapat dengan mudah dibuat oleh alat editor bingkai dan file frame itu dapat digunakan dengan fungsi dalam program PLC pengguna.

3. Layanan ini terutama digunakan untuk berkomunikasi antara PLC dan perangkat lain yang memiliki port RS-232C atau RS-422/485 dan membuka format protokol.

\section{Hasil dan Pembahasan}

\subsection{Hasil}

Diperolehnya kontrol sistem-ILST baru, dengan kecepatan yang lebih tinggi, flexibilitas tinggi, input output yang cukup handal, dengan software berbasis windows dan harga yang memadai dari anggaran yang diperoleh tiap tahun, tersedia di pasaran dalam negeri serta dapat berkomunikasi dengan existing kontrol sistem-ILST.

Dapat dipasangnya kontrol sistem baru di plant fasilitas-ILST dan dapat dioperasikannya plant fasilitas-ILST secara local dan remote untuk beroperasinya terowongan angin-ILST untuk menunjang pengujian aerodinamika aeronautika maupun non-aeronautika.

\subsection{Pembahasan}

Kegiatan pembaruan kontrol sistem terowongan angin-ILST baru meliputi :

1. Obsevasi existing PLC SattControl SC-60 dan SC-31.

2. Obsevasi PLC baru yang ada di pasaran dalam negeri.

3. Memutuskan PLC baru yang akan digunakan sebagai pengganti PLC lama.

4. Pembuatan kontrol sistem baru sebagai pilot project. 
5. Penerapan kontrol sistem pilot project pada salah satu plant fasilitas-ILST sebagai local kontrol.

PLC yang digunakan pada pilot project dipakai pada seksi uji Industrial pada tahun 2002

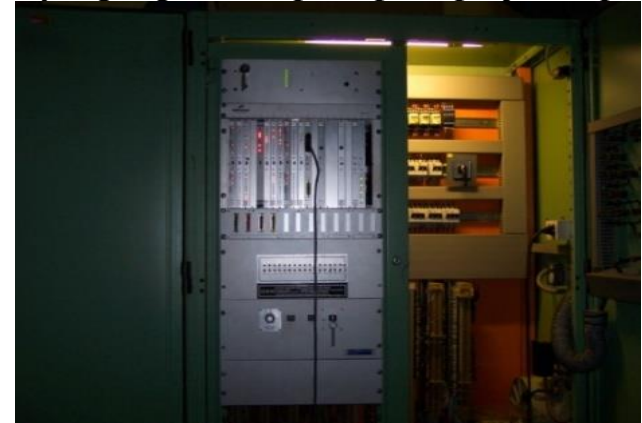

Gambar 15. PLC Industrial lama

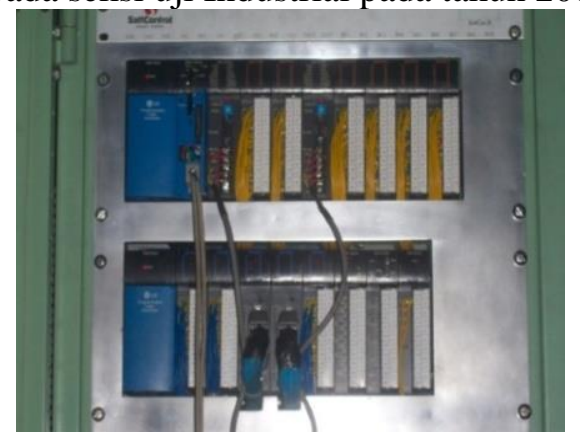

Gambar 16. PLC Industrial baru

6. Penerapan kontrol sistem baru yang dapat berkomunikasi dengan kontrol sistem lama (Central PLC).

7. Penerapan kontrol sistem baru pada beberapa plant fasilitas-ILST.

Pembaruan PLC dilanjutkan pada tahun 2004 sampai tahun 2013 seperti gambar dibawah

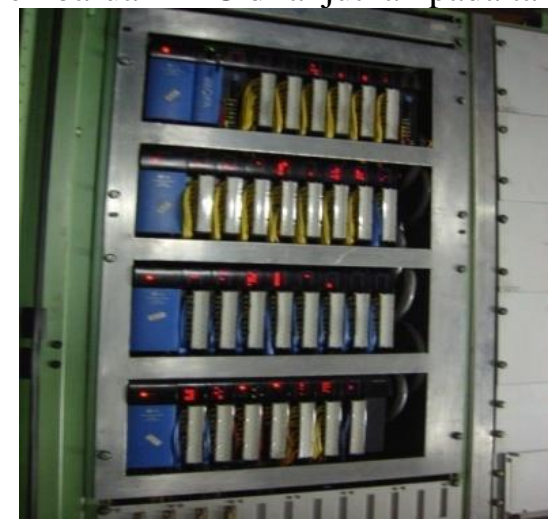

Gambar 17. PLC External balance 2004

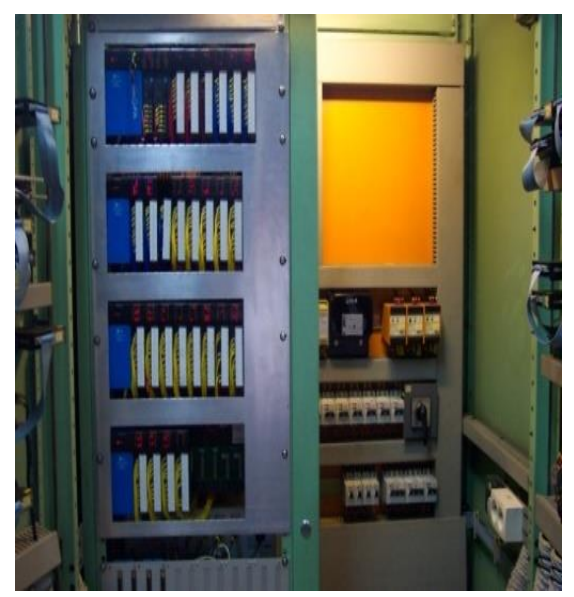

Gambar 19. PLC Cooling Sys 2005

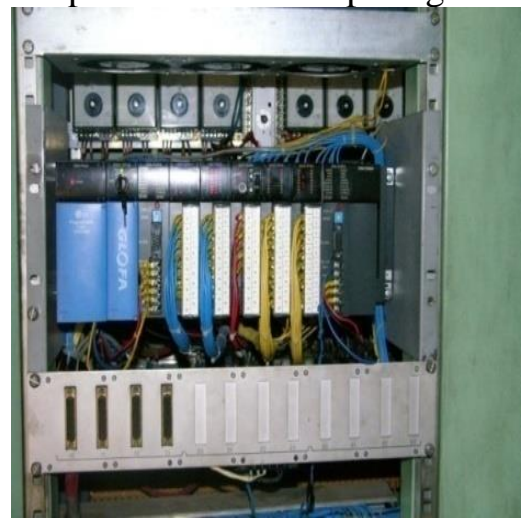

Gambar 18. PLC Fan drive 2004

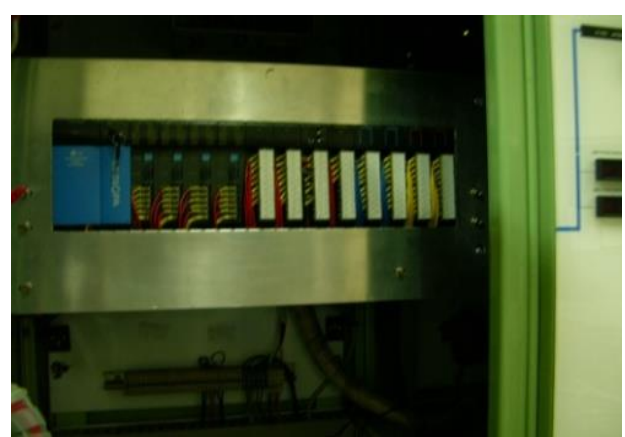

Gambar 20. PLC Massflow Control Sys 2006 


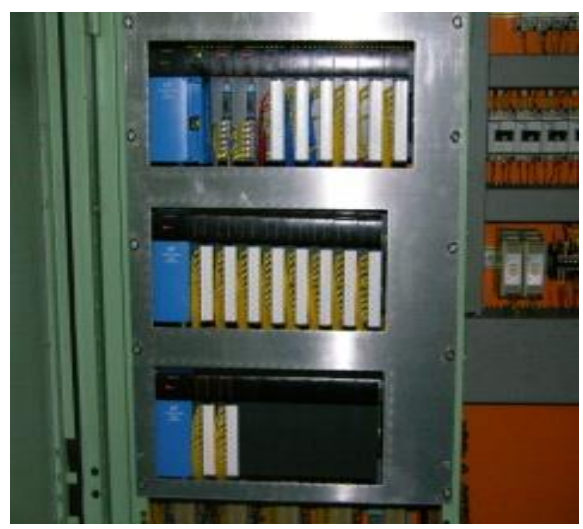

Gambar 21. Air Distribution Sys-2006

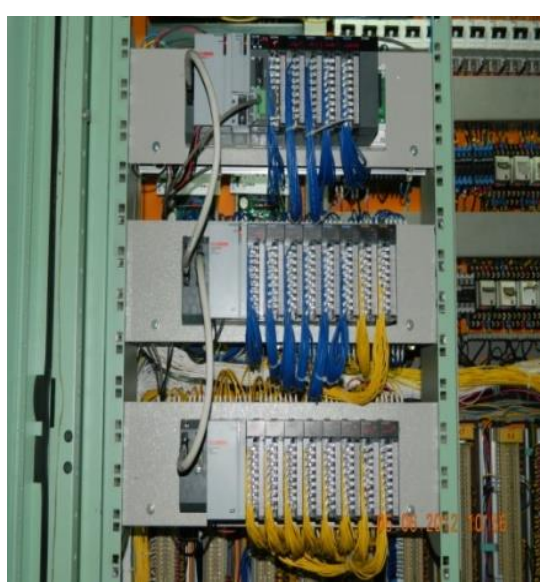

Gambar 23. PLC Sting Support 2012

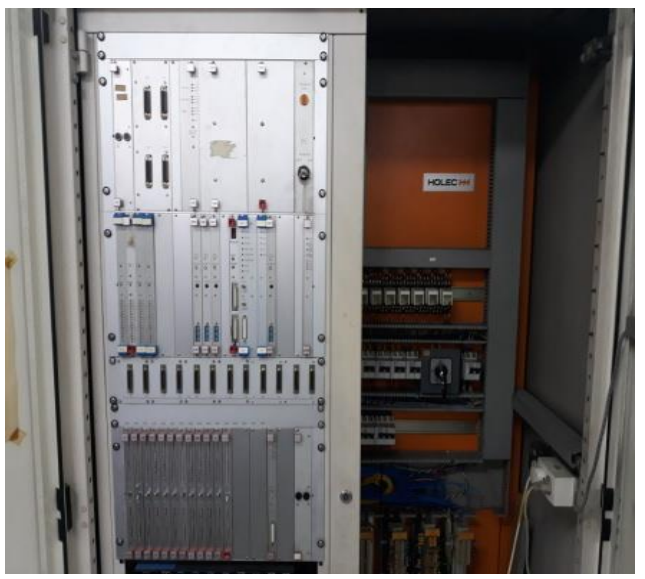

Gambar 25. Central PLC lama-2002

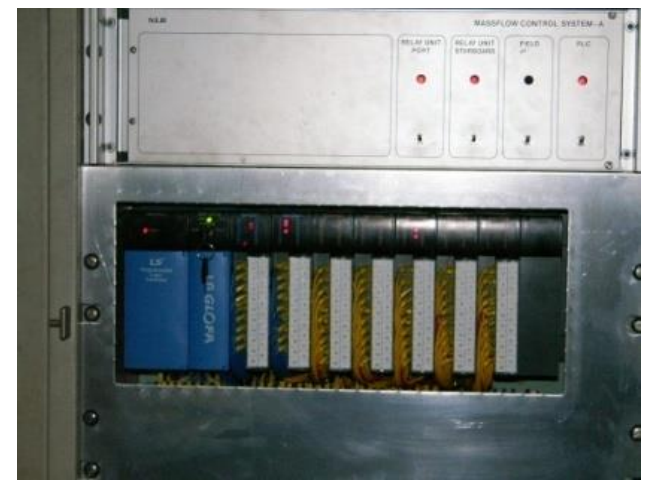

Gambar 22. Compress Air Sys-2006

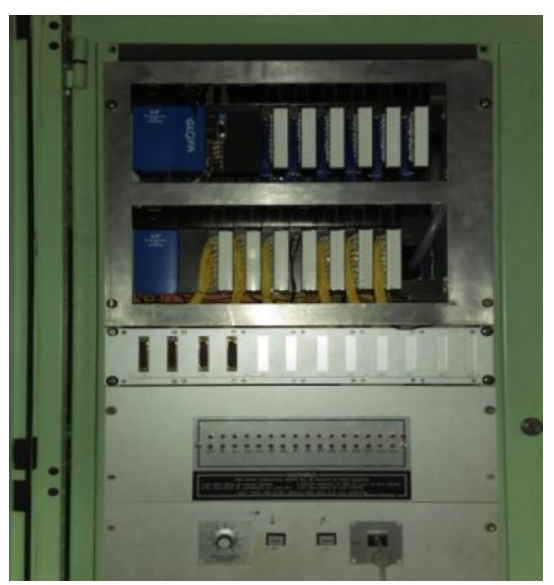

Gambar 24. PLC Empty box 2013

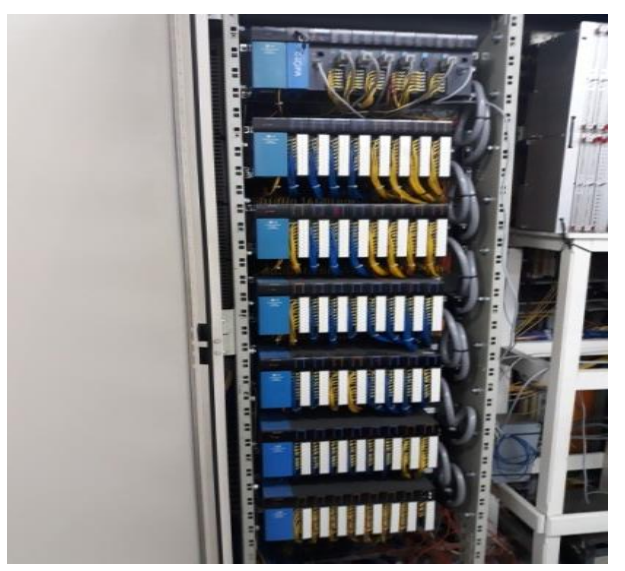

Gambar 26 Central PLC baru 2004 - 2013 


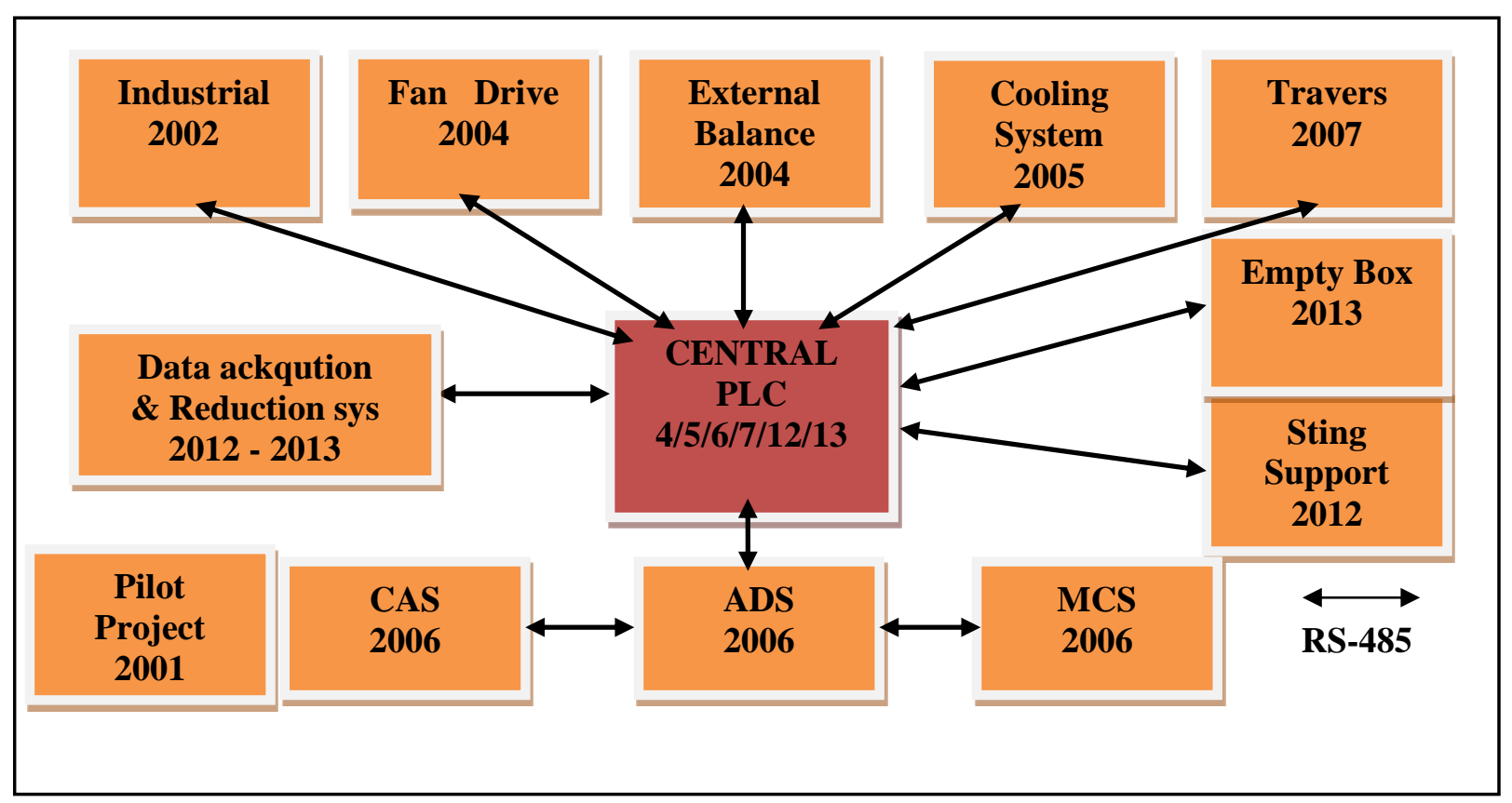

Gambar 27. Pembaruan Kontrol Sistem ILST

8. Penyempurnaan Kontrol sistem ILST

Tahapan ini merupakan tahapan meningkatkan kecepatan komunikasi antara local PLC ke Central PLC dan antara Central PLC dengan data akuisisi-ILST.

Pada tahun 2012 dimana ada kegiatan peningkatan kerja Data acqution and Reduction System (DARS) ILST.

Dilaksanakan modifikasi Central PLC untuk pengambilan data semua plant fasilitas ILST sebagai berikut :

a. Komunikasi antara Central PLC dan DARS melalui interface komunikasi serial RS-485, dengan jarak maximum 500meter, kecepatan maximal 57600 Bps, 2 kabel, jaringan multipoint, dimodifikasi menjadi point $b$.

b. Komunikasi antara Central PLC dan DARS melalui interface komunikasi F-net dengan jarak maximum $1 \mathrm{~km}$, kecepatan maximal $500 \mathrm{KBps}$, dimodifikasi menjadi point $\mathrm{c}$.

c. Komunikasi antara Central PLC dan DARS melalui interface komunikasi Ethernet dengan jarak maximum $2.5 \mathrm{~km}$, kecepatan maximal 500MBps.

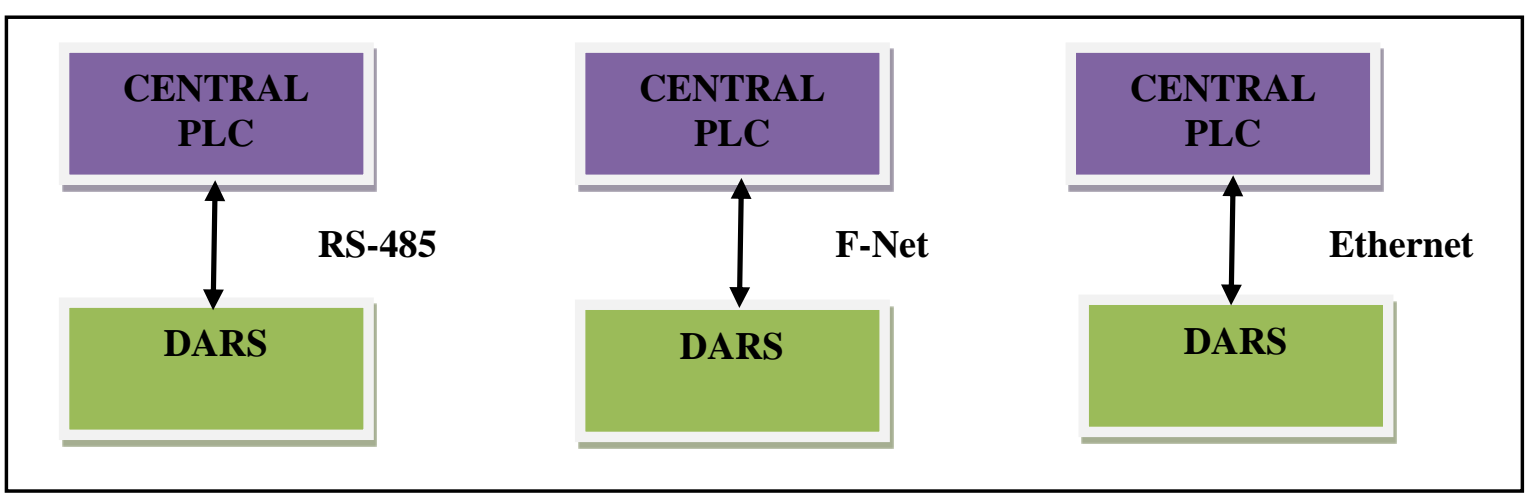

Gambar 28. Pembaruan Data Akuisisi Kontrol Sistem ILST 


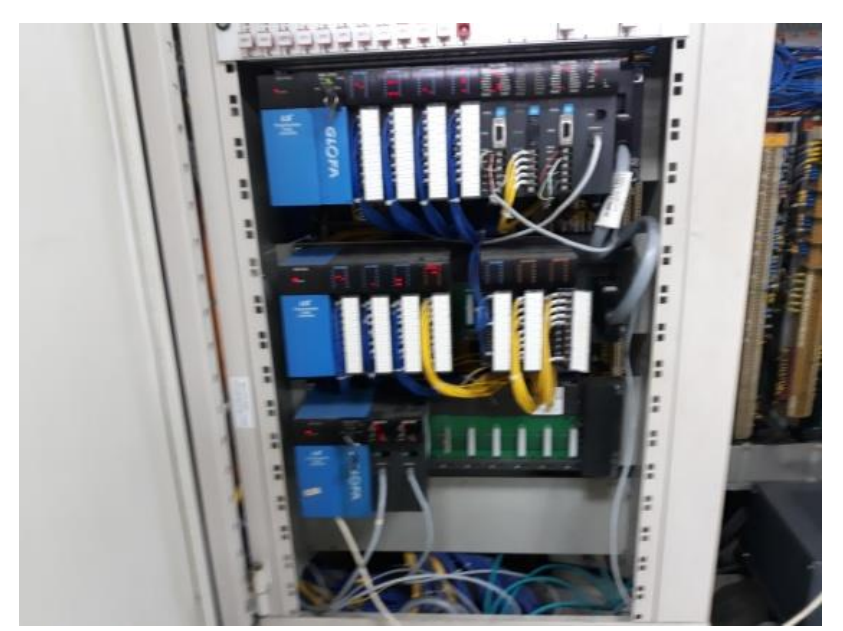

Gambar 29. Pembaruan Data Akuisisi Kontrol Sistem ILST

Pada saat ini komunikasi DARS dengan central PLC mengalami perolehan data plant fasilitas-ILST dengan data tak mulus (lompat-lompat nilainya) yang perlu dilanjutkan modifikasi komunikasi antara Central PLC dan Lokal PLC.

\section{KESIMPULAN DAN SARAN}

\section{A. KESIMPULAN}

Telah dilaksanakan pembaruan kontrol sistem ILST pada semua plant fasilitas-ILST dan telah digunakan untuk mendukung operasi terowongan angin-ILST sebagai berikut :

1. Pada plant fasilitas-ILST terpasang local PLC untuk operasi local kontrol dan central PLC untuk remote control, sampai saat ini masih digunakan dan belum rusak dan bermasalah, yang menunjukan kinerja processor dan memory PLC dengan jumlah I/O dan jenis kerjanya, sesuai penggunaanya dan cukup handal.

2. Komunikasi antara local PLC dan central PLC, central PLC dengan DARS menggunakan interface komunikasi RS-485, masih memenuhi kebutuhan penggunaannya tetapi setelah Pembaruan DARS dengan basis Ethernet tahun 2012, kecepatan komunikasi RS-485 sudah tak memadai lagi dan digunakan Ethernet sebagai pengganti RS-485 antara DARS dan central PLC.

3. Untuk pengujian model uji aerodinamika pesawat terbang secara step by step kecepatan komunikasi RS-485 masih memadai dan untuk pengujian model uji aerodinamika pesawat terbang secara continue kecepatan komunikasi RS-485 sudah tak memadai lagi.

\section{B. SARAN}

1. Setelah kegiatan pembaruan kontrol sistem ILST, diharapkan dapat dilanjutkan dengan perawatan kontrol sistem baru dan pembuatan back up software aplikasi setiap tahun dan penyediaan bateray back up.

2. Pembaruan komunikasi antara local PLC dan central PLC perlu dilakukan untuk tahapan penyempurnaan lebih lanjut, baik basis Ethernet maupun penggantian media komunikasinya.

3. Diperlukan pembuatan Human Machine Interface (HMI) baik untuk local kontrol sebagai antisipasi gagal komunikasi antara PLC.

\section{RUJUKAN}

[1] D. Petruzella Frank, Programmable Logic Controllers, Mc Graw Hill Education, fifth edition, 2017.

[2] Glofa GM-4 series Manual book, LGS, 2001.

[3] Stallings, William, Komunikasi data dan computer, Salemba Teknika, 2011.

[4] Tanenbaum, Andrew S., Prenhalindo \& Pearson, Jaringan Komputer, Education Asia Pte, Ltd, 2010. 